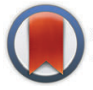

CrossMark \&lick for updates

Cite this: Phys. Chem. Chem. Phys. $2015,17,21364$

Received 11th February 2015, Accepted 5th March 2015

DOI: $10.1039 / \mathrm{c} 5 \mathrm{cp} 00884 \mathrm{k}$

www.rsc.org/pccp

\section{The adsorption of thiophenol on gold - a spectroelectrochemical study}

\begin{abstract}
Rudolf Holze
The adsorbate formed by adsorption of thiophenol on a polycrystalline gold electrode and brought into contact with aqueous solutions of $1 \mathrm{M} \mathrm{HClO}_{4}$ and $0.1 \mathrm{M} \mathrm{KClO}_{4}$ has been studied using cyclic voltammetry and surface-enhanced Raman spectroscopy. A strong adsorption is deduced from observations made using cyclic voltammetry. From the SER spectra, interactions of thiophenol with the gold surface via a gold-sulfur bond with the aromatic ring pointing away from the surface is concluded for both electrolyte solutions.
\end{abstract}

\section{Introduction}

Substantial interest has been devoted to studies of selfassembled monolayers (SAMs) formed in particular of sulfurcontaining (i.e. mostly -SH- and less frequently -SR-substituted) organic molecules on gold surfaces. ${ }^{1-3}$ Unfortunately the term SAM has gained a huge popularity although sometimes not matching the actual properties of the layers, in particular their degree of "organization", i.e. periodicity. As reported elsewhere ${ }^{4}$ the initially formed adsorbates are not necessarily well-organized and may reorganize on the surface into some better organized forms, ${ }^{5}$ but the highly organized arrangements frequently shown are not always obtained. Because SAMs on gold electrodes hold particular potential regarding the modification of the surface properties, patterning etc. published reports on electrochemical, spectroelectrochemical and surface-analytical studies are numerous. Somewhat surprisingly the most simple molecule thiophenol $\dagger$ TP has barely attracted attention beyond particular applications briefly reviewed below. Its adsorption on a mercury electrode has been studied, ${ }^{6}$ the Gibbs energy of adsorption $\Delta G_{\text {ad }}=-25.55 \mathrm{~kJ} \mathrm{~mol}^{-1}$ implies physisorption only. The respective value observed with a platinum electrode $\Delta G_{\text {ad }}=-41.0 \mathrm{~kJ} \mathrm{~mol}^{-1}$ (ref. 7) suggests a moderately stronger interaction in the range of chemisorption. No respective values for gold have been reported presumably because of the very strong gold-sulfur interaction making most methods employed in adsorption studies and based on adsorption/desorption equilibria unsuitable; ${ }^{8}$ the same applies apparently to silver. Data obtained for the adsorption of a number of other thio-compounds, in particular aliphatic ones, in the range $\Delta G_{\mathrm{ad}}=-80-100 \mathrm{~kJ} \mathrm{~mol}^{-1}$ again

Technische Universität Chemnitz, Institut für Chemie, AG Elektrochemie, 09107 Chemnitz, Germany. E-mail: rudolf.holze@chemie.tu-chemnitz.de

$\dagger$ Popular synonyms are: phenylmercaptan, benzenethiol.

imply very strong chemisorption. ${ }^{8}$ Various estimates and theoretical calculations reviewed by Ulman have resulted in a value of $167.15 \mathrm{~kJ} \mathrm{~mol}^{-1}$ for the Au-S-bond. ${ }^{9}$ In order to close the gap in structural information - the thermodynamic one will hardly be closed at all with electrochemical methods - and to extend the initial data reported in an exploratory study by Szafranski et $a l .{ }^{10}$ we have studied the adsorption of thiophenol on a polycrystalline gold electrode using cyclic voltammetry (CV) and surface-enhanced Raman spectroscopy (SERS). ${ }^{11}$

Carron and Hurley have used SERS and TP adsorbed on copper, silver and gold surfaces to determine the azimuthal angle at the sulfur atom. ${ }^{12}$ A study of TP adsorbed on gold nanoparticles has been reported by Li et al. ${ }^{13}$ wherein theoretical data pertaining to the various states of the adsorbate have been obtained using DFT and compared with experimental data. The forms of species considered in theory were as follows.

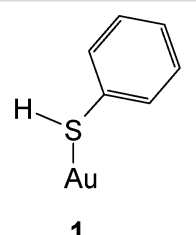

1

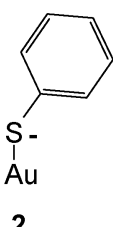

Scheme 1

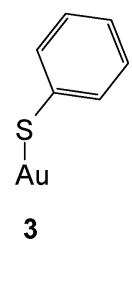

Gold was implemented as a single atom instead of a cluster or an even larger aggregate resembling a solid. Adsorption as a thiophenylate (or simply thiolate) (3) was deduced from a comparison of calculated and experimentally observed band positions. A band observed at $275 \mathrm{~cm}^{-1}$ was assigned to the $\mathrm{Au}-\mathrm{S}$ stretching mode. The calculated value of $334 \mathrm{~cm}^{-1}$ deviates strongly, presumably indicating the limited viability of representing a metal surface (even that of a nanoparticle) by 
a single metal atom. It should be noted that generally adsorption of thiols is assumed to proceed via release of a hydrogen atom according to

$$
\mathrm{R}-\mathrm{S}-\mathrm{H}+\mathrm{Au}_{x} \rightarrow \mathrm{RS}^{(-)} \mathrm{Au}^{(+)} \mathrm{Au}_{x-1}+1 / 2 \mathrm{H}_{2}
$$

Accordingly the distinction between 2 and 3 in the preceding scheme is applicable only for a discrete species as assumed for the DFT calculations, a negatively charged adsorbate $\mathrm{RS}^{(-)}$with a metal surface being expected only at sufficiently negative electrode potentials. Both theoretical and experimental evidence supporting this assumption and the distinction between $\mathrm{RS}$ and $\mathrm{RS}^{(-)}$ appears to be missing so far.

Further studies of adsorbed TP are available. In a study aiming at the separation of electromagnetic and chemical enhancement, Saikin et al. ${ }^{14}$ assigned a band at $415 \mathrm{~cm}^{-1}$ as being admixed with the $\mathrm{Au}-\mathrm{S}$ stretching mode. Wu et al. ${ }^{15}$ prepared differently shaped gold particles subsequently studied with SER supplemented with DFT-calculations wherein the gold surface was mimicked by 9-16 atoms. Some of the displayed spectra (without band assignment) showed a band around $250 \mathrm{~cm}^{-1}$ possibly associated with a gold-sulfur mode. Form 3 was deduced from DFT-calculations, also assuming the interaction of a single gold atom with TP by $\mathrm{Xu}$ et al. ${ }^{16}$ Surprisingly no band could be attributed to the $\nu_{\mathrm{Au}-\mathrm{S}}$ mode. Nara et $a l .{ }^{17}$ used an assembly of gold atoms arranged according to the Au(111) surface. The molecule was calculated with a tilting angle of $61^{\circ}$ with respect to the surface normal.

In most studies involving the use of TP the molecule is used as a marker or reporter molecule or simply as a probe to determine the suitability of a substrate for surface enhancement or to estimate an enhancement factor (for examples, see ref. 18-23, for recent overviews see ref. 24, on theory see ref. 25 and 26). Joo adsorbed TP and benzyl mercaptan on gold nanoparticles. ${ }^{27}$ Adsorption of the latter compound proceeded faster; at high bulk concentration of the adsorbate the obtained SER spectra were almost identical. At lower bulk concentration differences were observed, but neither a low-wavenumber band indicative of $\mathrm{Au}-\mathrm{S}$-interaction was observed nor band assignment and interpretation in terms of the adsorbate geometry were attempted. The suitability of gold colloids for SERS was examined by Xu et $a .^{28}$ using TP as a test molecule. TP induced the aggregation of the nanoparticles. Aggregation of gold nanoframes usually assumed to give enhanced scattering caused by the enhanced plasmonic field between the particles was found to actually reduce the enhancement of SERS by TP by Mahmoud and El-Sayed. ${ }^{29}$ The observations could be described and explained using a discrete dipole approximation. The observed and assigned bands showed different increases of enhancement as a function of the number of involved nanoframes and interparticle separation. The type of TP-gold interaction was not discussed. Gold nanoparticles arranged as dimers with hot spots at their point of contact were prepared and tested by Alexander et al. ${ }^{30}$ using TP as a test case. Only spectra in the fingerprint region were reported without band assignment, and a pronounced relationship between the plane of polarization of the illuminating light and the dimer axis was found. TP was employed as a test molecule to determine enhancement factors by Taylor et al. ${ }^{31}$ and to determine the actual surface areas by Buividas et al. ${ }^{32}$

Ren et $a l .{ }^{33}$ applied tip-enhanced Raman spectroscopy to TP adsorbed on $\mathrm{Au}(110)$. The spectra were hardly different from those of plain TP. No metal-sulfur mode was found, no molecular orientation was deduced. For further studies surface selection rules not specified were invoked. Employing the vibrational Stark effect Marr and Schultz have imaged electric fields in both SERS and TERS using TP as a probe. ${ }^{34}$ Fan et al. ${ }^{35}$ used TP as a test molecule for estimation of the damping effect of $\mathrm{a} \mathrm{SiO}_{2}$-shell on a gold nanoparticle. The electromagnetic enhancement was found to decrease with growing shell thickness. Wang et al. ${ }^{36}$ reported on $\mathrm{Au}-\mathrm{Ag}$-alloy nanoparticles with different compositions. TP was used as a probe molecule in subsequent studies using SERS. SER intensities increased with growing gold content at a laser wavelength of $\lambda_{0}=1064 \mathrm{~nm}$. Taking into account particle size and particle aggregation the higher gold content was related to the effect of surface plasmon resonance enhancement. SERS-active gold-silver nanofibers were prepared by electrospinning. ${ }^{37}$ The actually observed enhancement for TP (among other molecules) depended on the gold content. Ling et al. ${ }^{38}$ prepared silver nanowires coated with gold. The spectra reported for the fingerprint region suggest the suitability of the nanowires for SERS; no band assignments or vibrational band of a gold-sulfur mode were provided. Gold-coated silver particles prepared for an immunoassay were prepared by Cui et al. ${ }^{39}$ A pronounced dependency of the SERS-intensity on the metallic composition was found, and the intensity was generally stronger by a factor of ten when compared with silver nanoparticles. Monodisperse gold octahedra were prepared by Chang et al. ${ }^{40}$ The surface plasmon resonance was found to increase with the particle size. Using TP as a test molecule, the suitability of the substrate for SERS was examined. The maximum enhancement was found at a particle size of $90 \mathrm{~nm}$, and no signal at all was found at $\sim 120 \mathrm{~nm}$. Substrate effects of gold nanospheres and nanocubes have been reported by Mahmoud ${ }^{41}$ and Mahmoud and El-Sayed ${ }^{42}$ without information regarding the adsorbate structure. Bhuvana et al. ${ }^{43}$ prepared carbon-assisted electroless gold as SERS substrate and observed an enhancement factor of $10^{6}-10^{7}$ for TP adsorbed on this substrate. Slightly smaller enhancement factors were observed by Kim et $a .^{44}$ for patterned gold nanoparticle films with adsorbed TP. Li et al. ${ }^{45}$ and Ge et al. ${ }^{46}$ used TP as a reporter molecule on gold colloids subsequently employed in an immunoassay.

Tao et al. ${ }^{47}$ have studied adsorbates of TP, benzyl mercaptan, biphenylthiol and 4-biphenylmethanethiol without and with alkoxy-substituents in the para-position on gold electrodes obtained by evaporation of gold on mica (see Scheme 2). The results of cyclic voltammetry, ellipsometry, scanning tunneling microscopy and infrared spectroscopy imply that for all benzyl mercaptans and 4-biphenylmethanethiols closely packed and ordered monolayers are formed. TP and biphenylthiols yield lower surface coverages. With longer $p$-alkoxy-chains increasing intermolecular interaction and closer packing are found. These subtle differences in behavior were attributed to the bond angle situation at the thiolate head group being in an interplay with 
intermolecular interactions. Theoretical calculations assuming both $\mathrm{sp}^{3}$ - and sp-hybridization with respective adsorbate geometries have been reported $;^{48,49}$ unfortunately experimental evidence (in particular vibrational spectra) supporting the suggested sp-hybridization is lacking so far.

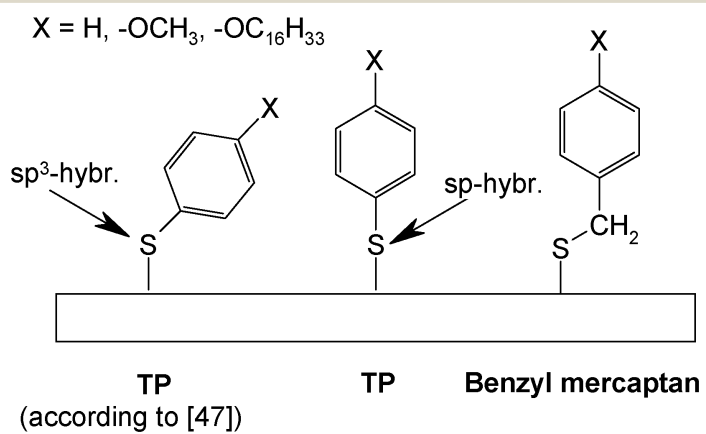

Scheme 2

Formation of poorly defined SAMs from TP was also deduced from contact angle measurements and ellipsometry by Sabatani et al. ${ }^{50}$

Several publications dealing with substituted TP (namely 4-nitrothiophenol, 4-amino-thiophenol ${ }^{51}$ etc.) are available, mostly these molecules serve just as probes like TP, metalsulfur vibrations are not mentioned. Dithiols, i.e. molecules with two -SH-units, show particularly poor organization. ${ }^{4}$

Somewhat surprisingly for TP and substituted TPs adsorbed on silver a corresponding silver-sulfur vibration was repeatedly not observed. ${ }^{52-55}$ Nevertheless, molecular adsorbate orientations ranging from flat ${ }^{54}$ to perpendicular ${ }^{55}$ were suggested based on the dominance of an in-plane mode indicative of perpendicular orientation. ${ }^{55-57}$ Only Joo et al. ${ }^{58}$ have observed a band as a shoulder at $237 \mathrm{~cm}^{-1}$ assigned to the $\nu_{\mathrm{Ag}-\mathrm{S}}$; however, the authors concluded somewhat reluctantly a face-on adsorption on the surface of the silver sol particles.

Given this large body of both experimental and theoretical evidence the present study attempts to close an apparent gap: the lack of a structural model of TP adsorbed on a polycrystalline gold surface in contact with an electrolyte solution. Based on results of electrochemical experiments (cyclic voltammetry CV) and SERS the mode of adsorbate-surface interaction, the orientation of the adsorbed molecule with respect to the surface and its chemical state taking into account solution $\mathrm{pH}$ should be deduced.

\section{Experimental}

CVs were recorded using gold sheet working electrodes using aqueous solutions of $1 \mathrm{M} \mathrm{HClO}_{4}$ (Acros, p.A.) and $0.1 \mathrm{M} \mathrm{KClO}_{4}$ (Merck, p.A., $\mathrm{pH}=4.90$, unbuffered) as supporting electrolytes and a custom-built potentiostat interfaced with a standard PC via an ADDA-converter card operated using custom developed software. A relative hydrogen reference electrode ${ }^{59,60}$ was used in the experiments with the acidic electrolyte solution, with the solution of $0.1 \mathrm{M} \mathrm{KClO}_{4}$ a mercurous sulfate electrode $\left(E_{\mathrm{MSE}}=0.375 \mathrm{~V} v\right.$. a saturated calomel electrode SCE and $1.252 \mathrm{~V} v s$. RHE in this electrolyte solution) was employed in order to avoid contamination of the electrolyte solution with specifically adsorbing chloride ions. A gold sheet was used as the counter electrode in an H-cell with compartments separated by glass frits.

SER spectra were recorded on an ISA T64000 spectrometer connected to a Spectraview 2D CCD detection system using $\lambda_{0}=$ $647.1 \mathrm{~nm}$ excitation laser light provided by a Coherent Innova 70 Series ion laser, the laser power was measured at the laser head with a Coherent 200 power meter. Normal Raman spectra of liquid thiophenol were recorded for comparison on a MonoVista CRS High Resolution spectrometer at $\lambda_{0}=473 \mathrm{~nm}$ with exciting laser light provided by a Cobolt solid state laser at approx. $8 \mathrm{~mW}$ laser power at the sample. Infrared spectra were acquired on a BioRad FTS40 instrument at $2 \mathrm{~cm}^{-1}$ resolution with 32 scans and baseline-correction.

Roughening of the gold electrode (Schiefer, Hamburg, polycrystalline $99.99 \%$, polished down to $0.3 \mu \mathrm{m} \mathrm{Al}_{2} \mathrm{O}_{3}$ to ascertain a defined clean surface state) employed to confer SERS activity was performed in a separate cell with an aqueous solution of $0.1 \mathrm{M} \mathrm{KCl}$ by cycling the electrode potential between $E_{\mathrm{SCE}}=$ $-0.8 \mathrm{~V}$ and $E_{\mathrm{SCE}}=1.65 \mathrm{~V}$ for about 10 minutes. ${ }^{61}$

Electrolyte solutions were prepared from 18 MOhm water (Seralpur Pro 90 c), thiophenol (Merck, z.S., used as received), perchloric acid (Acros, p.A.), and $\mathrm{KClO}_{4}$ (Merck, Suprapur). All solutions were freshly prepared, purged with nitrogen $(99.999 \%)$, and all experiments were performed at room temperature $\left(20{ }^{\circ} \mathrm{C}\right)$.

Adsorption of thiophenol on the gold electrodes was performed by exposing the electrodes for $5 \mathrm{~min}^{31}$ to 1 hour ${ }^{62}$ to its solution (5 and $1 \mathrm{mM}$ ) in absolute ethanol (VWR, AnalaR, min. $99.8 \%$ ) without any electrode potential control.

\section{Results and discussion}

Cyclic voltammograms recorded in an aqueous $1 \mathrm{M} \mathrm{HClO}_{4}$ electrolyte solution with a gold electrode without and with preadsorbed thiophenol $\left(t_{\mathrm{ad}}=5 \mathrm{~min}\right.$ if not stated otherwise) starting at the negative potential limit are displayed in Fig. 1. In the positive going scan a substantial change in the current wave associated with the formation of the gold hydroxide/oxide layer is found. The cathodic reduction peak associated with the reductive conversion of the gold oxide/hydroxide surface layer is somewhat diminished. Thus this layer has been formed to a smaller extent. Consequently a substantial portion of the anodic charge must have been consumed in oxidation or at least oxidative desorption of the adsorbed thiolate. No attempt has been made to estimate the amount of coverage as applied elsewhere. ${ }^{63}$ The duration of the adsorption (ranging from 5 to $60 \mathrm{~min}$ according to ref. 31 and 62) did not show qualitatively different results. The estimated amount of coverage deduced from the anodic charge was only slightly larger with a longer adsorption time as evidenced in the inset of Fig. 1. Consequently, all experiments were performed with the shorter adsorption time of $5 \mathrm{~min}$.

CVs recorded in an aqueous $1 \mathrm{M} \mathrm{HClO}_{4}$ electrolyte solution with a gold electrode without and with preadsorbed thiophenol $\left(t_{\mathrm{ad}}=5 \mathrm{~min}\right)$ from the spontaneously established rest potential 


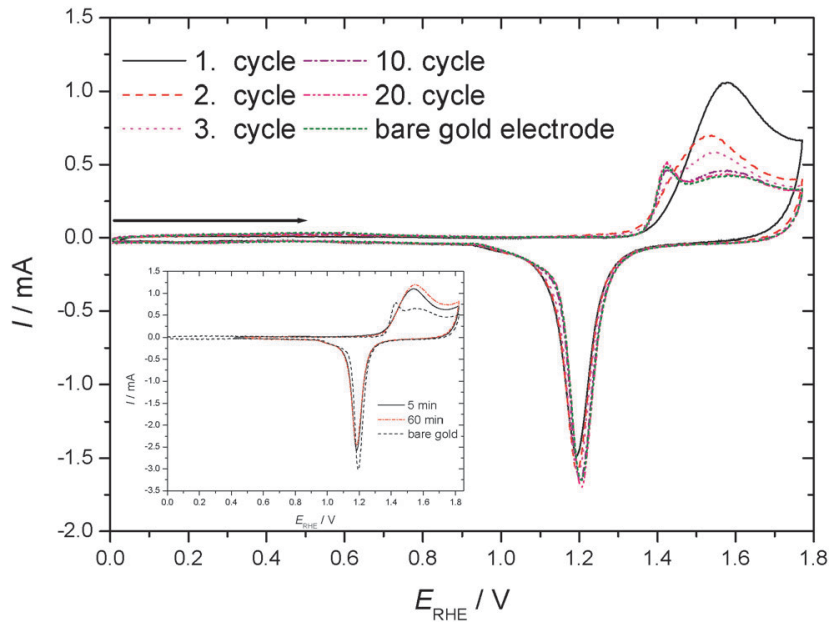

Fig. 1 Cyclic voltammograms of a gold sheet electrode without/with adsorbed TP in an aqueous solution of $1 \mathrm{M} \mathrm{HClO}_{4}$ (full electrode potential cycles); $\mathrm{d} E / \mathrm{d} t=0.1 \mathrm{~V} \mathrm{~s}^{-1}$, room temperature, nitrogen purged. Inset: effect of adsorption time.

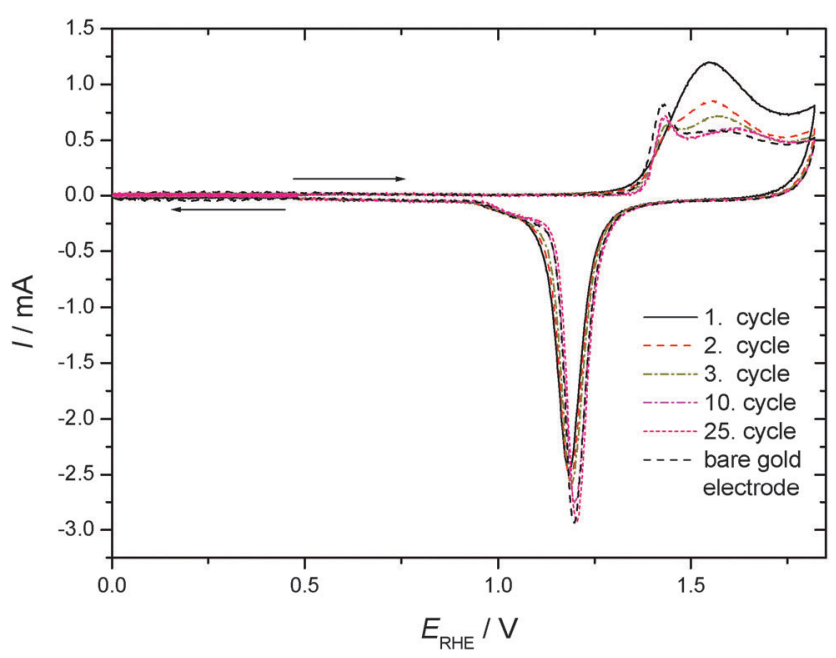

Fig. 2 Cyclic voltammograms of a gold sheet electrode without/with adsorbed TP in a solution of $1 \mathrm{M} \mathrm{HClO}_{4}$ (partial cycles starting at spontaneous established rest potential, arrows indicate direction of scan with starting point of arrow indicating initial electrode potential); $\mathrm{d} E / \mathrm{d} t=0.1 \mathrm{~V} \mathrm{~s}^{-1}$, room temperature, nitrogen purged.

towards anodic and cathodic directions are displayed in Fig. 2. This procedure does not risk electrode-potential induced changes, in particular desorption, caused by the initial potential step proceeding in the potential-time procedure applied for Fig. 1 where the electrode potential is switched from the rest potential established spontaneously at open circuit to the starting potential at the negative limit of the potential window where the first scan is initiated. No evidence of cathodic desorption or adsorbate reduction as reported elsewhere with e.g. 4-mercaptopyridine ${ }^{64,65}$ is found in the negative going scan. In the positive going scan, again, a substantial change in the current wave associated with the formation of the gold hydroxide/oxide layer is found. Differences between the current response of the covered and the uncovered electrodes are similar to those observed with the different potential-time regime applied in the previous experiment (see Fig. 1). After about ten electrode potential cycles reaching into the oxygen evolution region the $\mathrm{CV}$ of a pristine, uncoated gold electrode is observed. Assuming that strength of interaction - in the remaining absence of precise thermodynamic data - can be related qualitatively to the number of electrode potential scans necessary to remove an adsorbate; this observation agrees closely with results obtained with e.g. 4-mercaptobenzonitrile. ${ }^{66}$

CVs recorded using TP adsorbed on a polycrystalline gold electrode subsequently exposed to an aqueous electrolyte solution of $0.1 \mathrm{M} \mathrm{KClO}_{4}$ are shown in Fig. 3 for positive and negative going potential scans always starting at the spontaneously established rest potential. In comparison to the results obtained with an acidic electrolyte solution of well-defined $\mathrm{pH}$-value a significantly different picture emerges. Oxidation of the gold electrode surface is strongly inhibited at less positive electrode potentials, but the anodic current finally observed at more positive potentials is more than double the value recorded with the supporting electrolyte solution. The associated reduction feature in the return scan usually assigned to a less strongly bound surface oxide, which is thus more easily reduced, is the same as that observed with the blank electrolyte solution, whereas the second reduction peak (at lower electrode potential) is almost absent. Accordingly the anodic current must be associated with formation of the less strongly bound surface oxide, and some charge (when taking the anodic charge as a measure) is consumed by an oxidative process involving TP without the formation of a strongly bound surface oxide.

SER spectra of TP preadsorbed on a roughened gold electrode in contact with an aqueous solution of $1 \mathrm{M} \mathrm{HClO}_{4}$ are displayed in Fig. 5, as the reference vibrational spectra of TP are shown in Fig. 4. Assignment of bands as listed in Table 1 is based on literature data. ${ }^{58,67-72}$ Interpretation of SER spectra aiming at elucidation of structural information ranging in the present case from the mode of interaction between TP and the gold surface to

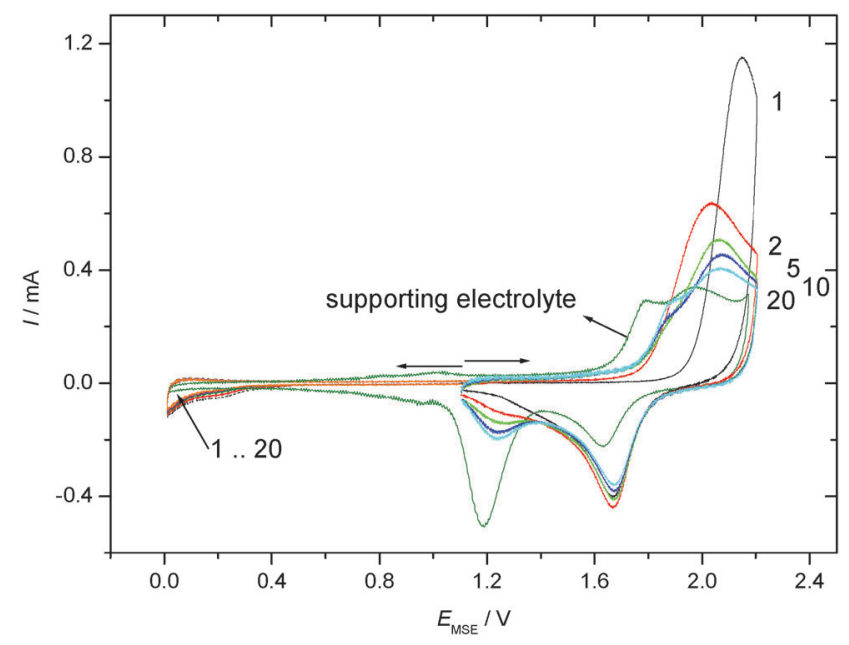

Fig. 3 Cyclic voltammograms of a gold sheet electrode without/with adsorbed TP in a solution of $0.1 \mathrm{M} \mathrm{KClO}_{4}$ (full cycle, arrows indicate direction of scan with starting point of arrow indicating initial electrode potential); $\mathrm{d} E / \mathrm{d} t=0.1 \mathrm{~V} \mathrm{~s}^{-1}$, room temperature, nitrogen purged. 


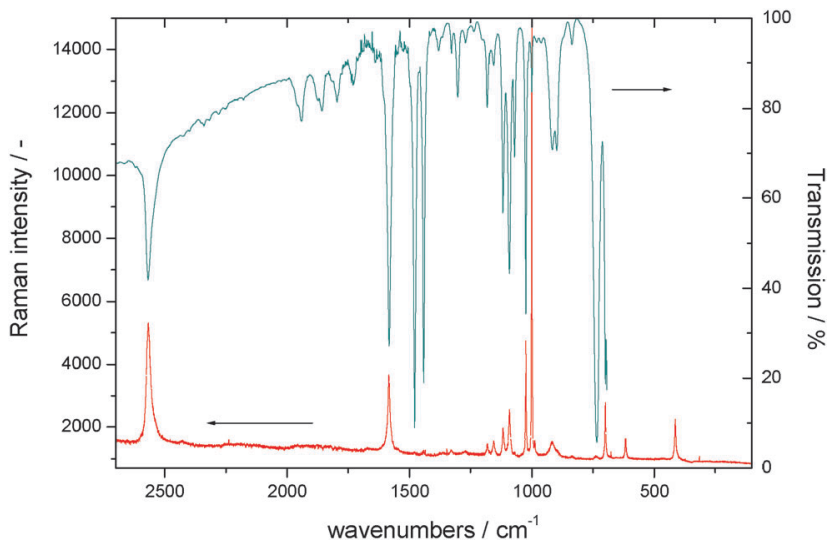

Fig. 4 Normal Raman and infrared spectra of thiophenol. possible intermolecular interactions up to SAM-formation is based on (1) identification and assignment of bands not observed with the bulk molecule, changes in (2) band position and (3) intensity, for an introductory overview see ref. 73. The spectra show a band around $265 \mathrm{~cm}^{-1}$, which does not appear for liquid thiophenol (Fig. 4), ${ }^{70}$ becoming more pronounced and shifting towards lower wavenumbers with more positive electrode potentials. The shift implies a weaker bond at more positive electrode potentials. This in turn would not support adsorption of TP as a negatively charged species (see 2 in Scheme 1) but instead as an intact molecule $\mathrm{R}-\mathrm{S}-\mathrm{H}$ (showing a substantially weaker $\mathrm{Au}-\mathrm{S}$ bond energy according to Li et al. ${ }^{13}$ ) or as thiolate $\mathrm{C}_{6} \mathrm{H}_{5} \mathrm{~S}$ - as also proposed by Li et al. ${ }^{13}$ Confusion with the $\mathrm{C}-\mathrm{S}$ in-plane bending mode observed by Li et $a l .{ }^{13}$ at

Table 1 Spectral data of thiophenol and thiophenol adsorbed on a gold electrode at various electrode potentials from an aqueous solution of $1 \mathrm{M}$ $\mathrm{HClO}_{4}$, all assignments based on literature data ${ }^{58,67-72}$

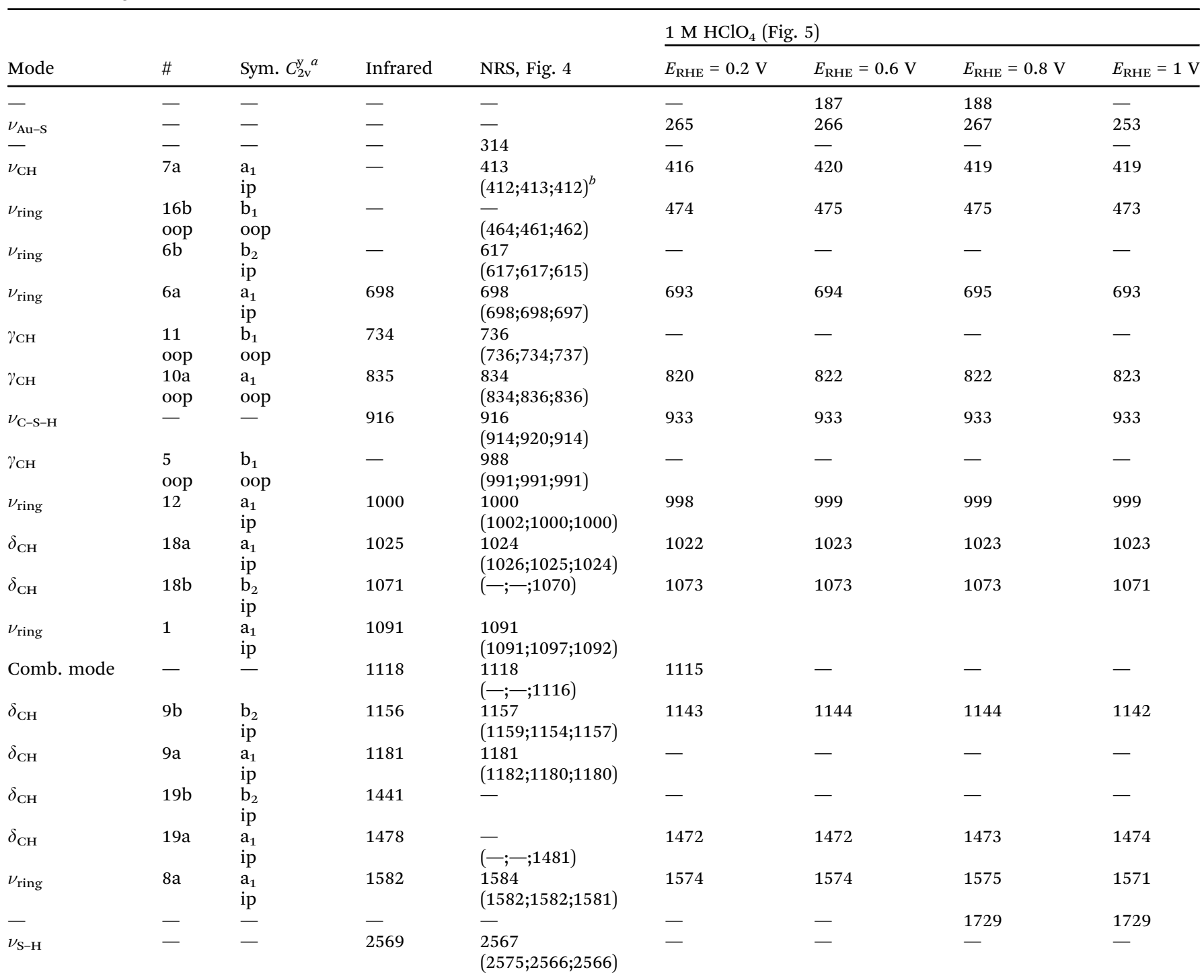

$\delta=$ in-plane deformation, $\gamma=$ out-of-plane deformation, $\nu=$ stretching, $\nu_{\mathrm{s}}=$ symmetric stretching. $\beta_{\text {as }}=$ rocking, $\nu_{\mathrm{s}}=$ wagging, $\beta_{\mathrm{s}}=$ scissoring, $\#=$ Wilson mode number, all modes in-plane if not stated otherwise oop: out-of-plane. ${ }^{a}$ Sometimes this is approximated as $C_{2 \mathrm{v}}(e . g$. in ref. 68$)$. ${ }_{b}$ Numbers in bracket refer to the assignments bei Varsanyi ${ }^{69}$ (first value), Kohlrausch ${ }^{67}$ (second value), and Scott et al. ${ }^{68}$ (third value); \#: Wilson mode number. 


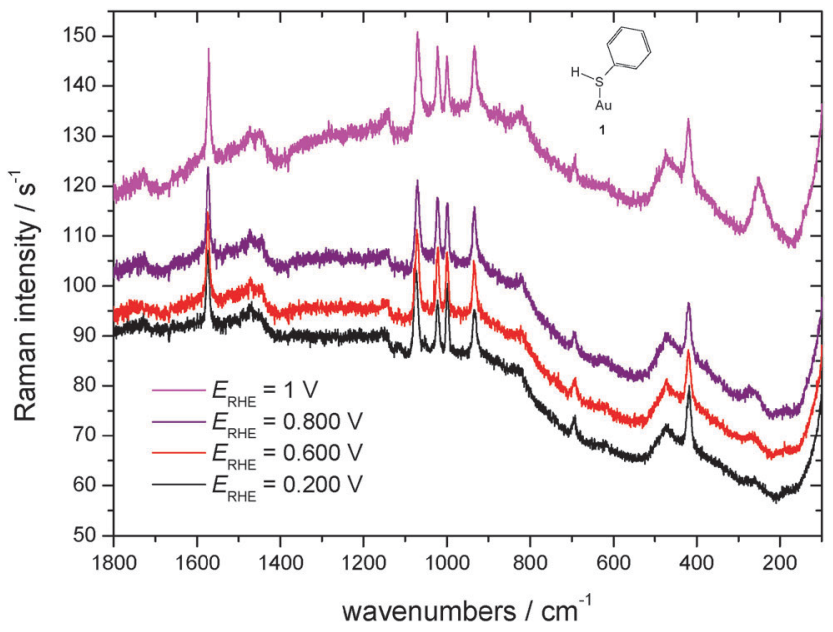

Fig. 5 SER-spectra of TP adsorbed on a polycrystalline gold electrode, aqueous solution of $1 \mathrm{M} \mathrm{HClO}_{4}$, room temperature, nitrogen purged, for experimental conditions see text.

$274 \mathrm{~cm}^{-1}$ with liquid TP but not seen here (see Fig. 4) is only theoretically possible, the extreme enhancement needed to support such assignment with the concomitant absence of a gold-sulfur mode makes it very unlikely. Distinction between the two options 1 and 3 (Scheme 1) is possible based on the intensity patterns and band positions reported by Li et al. ${ }^{13} \mathrm{In}$ the present case adsorption as intact TP can be deduced when taking into account the pronounced band at $933 \mathrm{~cm}^{-1}$ assigned to the $\mathrm{C}-\mathrm{S}-\mathrm{H}$ bending mode. The presence of a hydrogen atom at the sulfur atom will presumably have only a small steric effect pushing the aromatic ring closer to the metal surface and possibly diminishing surface enhancement of in-plane modes. This argument will thus hardly help to explain the lower overall SERS intensity.

For comparison SER spectra of related adsorbates interacting via the sulfur atom with the gold surface can be used. Several studies of thiol compounds adsorbed on gold surfaces by various authors have been reported, ${ }^{10,12,74,75}$ for a brief overview see also ref. 65. Joo et al. ${ }^{75}$ found a band at $227 \mathrm{~cm}^{-1}$ with benzyl phenyl sulfide adsorbed on a gold sol and assigned it to the Au-S stretching mode. Kang et al. assigned a band found for cyclohexyl isothiocyanate adsorbed at gold surfaces at 251 and $261 \mathrm{~cm}^{-1}$ (surprisingly depending on the adsorbate concentration in the deposition solution) to the $\mathrm{Au}-\mathrm{S}$ stretching mode. ${ }^{76} \mathrm{~A}$ band at $264 \mathrm{~cm}^{-1}$ was assigned by Bron and Holze ${ }^{64,65}$ to the Au-S stretching of 4-mercaptopyridine adsorbed on a gold substrate. With the isomeric 2-mercaptopyridine this band was found at $235 \mathrm{~cm}^{-1} .{ }^{63}$ In a SERS study of adsorbed benzenethiol on gold a mode at $275 \mathrm{~cm}^{-1}$ not visible in the displayed spectra was assigned to the Au-S stretching. ${ }^{12}$ Szafranski et al. ${ }^{10}$ noticed a band at $270 \mathrm{~cm}^{-1}$ which was tentatively assigned either to the ring vibration mode $\nu_{15}$ or a gold-sulfur mode. Mode $\nu_{15}$ was neither observed in spectra of neat TP by Szafranski et al. nor by us (see Fig. 4); elsewhere, this band has been classified as weak. ${ }^{69}$ Thus the band $265 \mathrm{~cm}^{-1}$ can be indeed assigned to the goldsulfur mode implying an adsorbate orientation with the benzene ring pointing away from the electrode surface on the surface.
Comparison of band intensities may provide evidence regarding molecular orientation. Although surface selection rules of the clear-cut type effective for infrared reflection spectroscopy as deduced by Greenler ${ }^{77}$ are not available for SERS more complex ones have been deduced (see e.g. see ref. 78-82). As concluded elsewhere based on ample evidence particularly from comparative studies employing other tools of surface science vibrational modes perpendicular to the surface are particularly intense. ${ }^{83,84}$ Assuming in slight simplification $C_{2 \mathrm{v}}$ symmetry of TP the vibrational modes can be classified into in-plane $a_{1}$ and $b_{2}$ modes and out-of-plane $a_{2}$ and $b_{1}$ modes with all modes being Raman-active. Interaction with the surface may further reduce symmetry and at least generally speaking - cause further Raman-silent modes to become active. As collected in Table 1 almost all observed bands are of the in-plane type. Thus it can be concluded, that TP is oriented with the aromatic ring pointing away from the electrode surface. A distinction between the suggested sp- or $\mathrm{sp}^{3}$-hybridization and the corresponding bond angles is not possible with the evidence reported here and in the absence of vibrational spectroscopic evidence of sp-hybridization.

In Fig. 6 SER spectra of TP adsorbed on a polycrystalline gold electrode in contact with an aqueous electrolyte solution of $0.1 \mathrm{M} \mathrm{KClO}_{4}$ are shown, band positions and assignments are collected in Table 2. A prominent change of relative intensity concerns the band at $933 \mathrm{~cm}^{-1}$ assigned to the $\mathrm{C}-\mathrm{S}-\mathrm{H}$ bending mode. Its relative weakness implies a relatively smaller amount of adsorbed R-S-H; accordingly R-S-dominates. The band assigned to the Au-S stretching mode is relatively weaker, its position shifts with positively going electrode potential to higher wavenumbers. Assuming thiolate as the adsorbed species the interaction (i.e. bond) will become stronger simply because of electrostatics (for other strongly adsorbed species see e.g. ref. 61).

No further significant changes in band positions and relative intensities are observed for both electrolyte solutions. This is in agreement both with the almost covalent attachment of the molecule via the sulfur atom and an orientation of the molecule away from the surface with less exposure to the electric field in the electrochemical double layer possibly yielding band shifts.

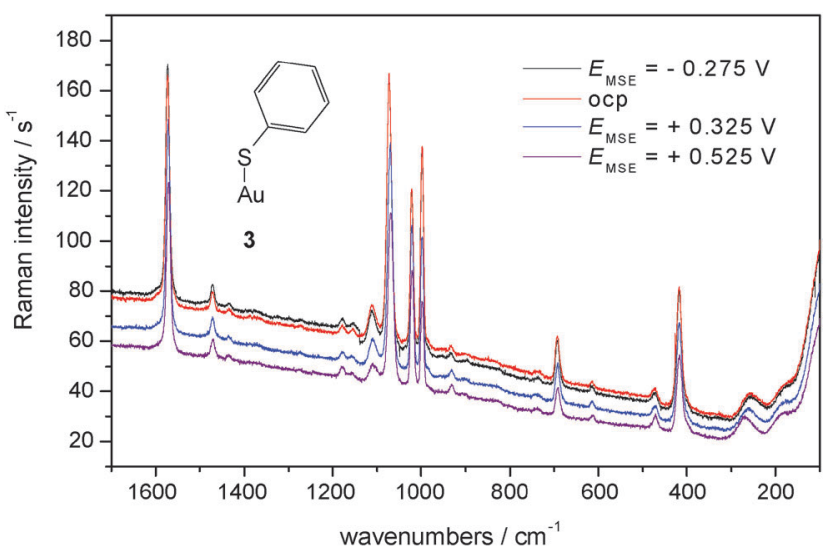

Fig. 6 SER-spectra of TP adsorbed on a polycrystalline gold electrode, aqueous solution of $0.1 \mathrm{M} \mathrm{KClO}_{4}$, room temperature, nitrogen purged, for experimental conditions see text. 
Table 2 Spectral data of thiophenol and thiophenol adsorbed on a gold electrode at various electrode potentials from an aqueous solution of $0.1 \mathrm{M}$ $\mathrm{KClO}_{4}$, all assignments based on literature data ${ }^{58,67-72}$

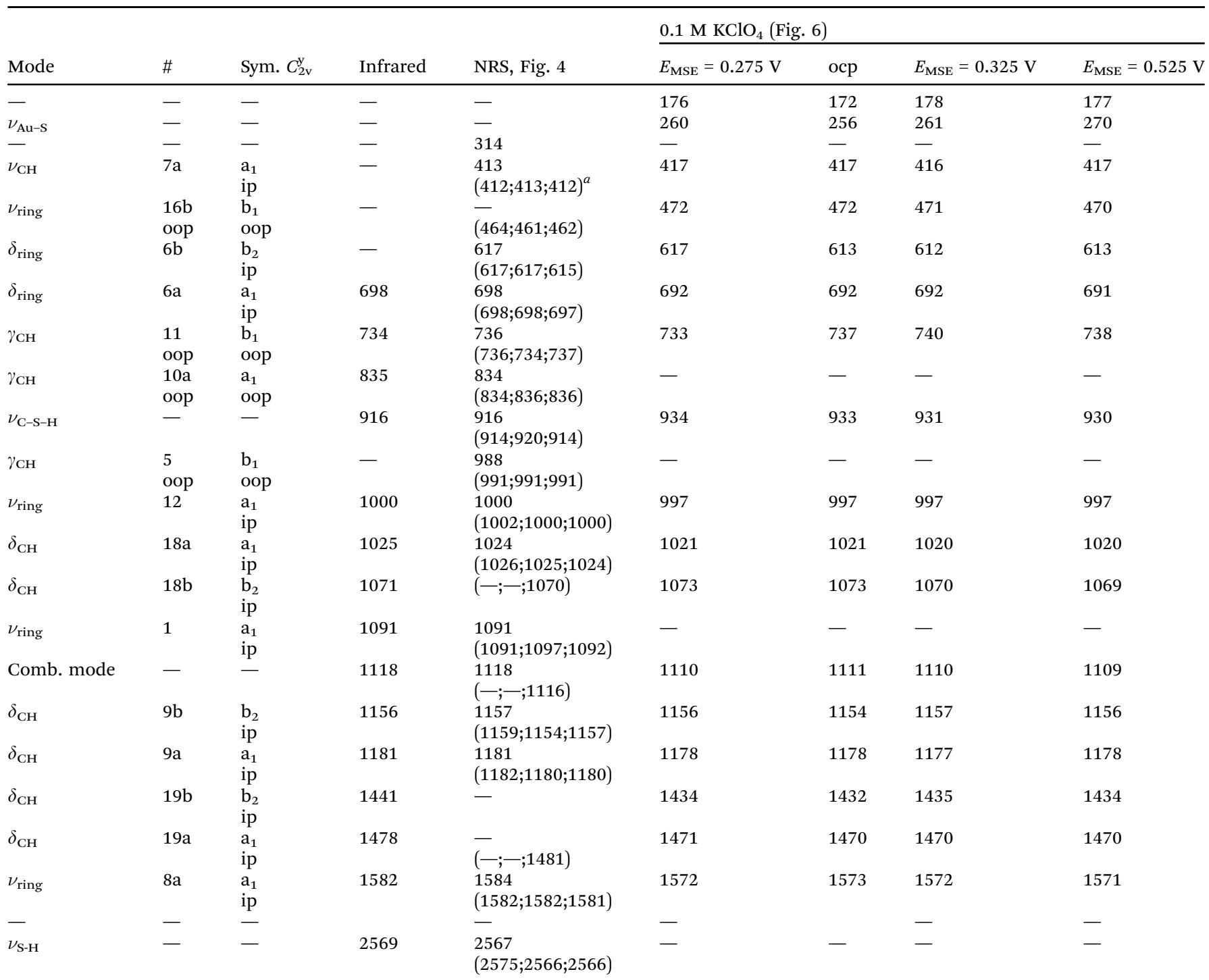

$\delta=$ in-plane deformation, $\gamma=$ out-of-plane deformation, $\nu=$ stretching, $\nu_{\mathrm{s}}=$ symmetric stretching. $\beta_{\text {as }}=$ rocking, $\gamma_{\mathrm{s}}=$ wagging, $\beta_{\mathrm{s}}=$ scissoring, $\#=$ Wilson mode number, all modes in-plane if not stated otherwise oop: out-of-plane. ${ }^{a}$ Numbers in bracket refer to the assignments bei Varsanyi ${ }^{69}$ (first value), Kohlrausch ${ }^{67}$ (second value), and Scott et al. ${ }^{68}$ (third value); \#: Wilson mode number.

A striking difference between SER spectra obtained in acidic and neutral solution is the overall scattering intensity. The generally much larger one with the neutral solution indicates a larger coverage or a pH-dependent orientation of the scattering molecules; surface enhancement itself does not appear to be pH-dependent. The difference in intensities can be rationalized when considering the $\mathrm{pH}$-dependent dissociation equilibrium of TP. In the almost neutral electrolyte solution a larger fraction of thiolate ions may be available for adsorption, and although the dominating driving force of adsorption is the gold-sulfur bond energy the electrostatic interaction in particular at electrode potentials positive to the potential of zero charge $E_{\mathrm{pzc}}(-0.18<$ $E_{\text {pzcus.SHE }}<0.34 \mathrm{~V}$, i.e. $-0.893<E_{\text {pzcvs.MSE }}<-0.313 \mathrm{~V}$, ref. 8) appears to assist in adsorption yielding a higher coverage. In acidic solution the protonated form prevails and is adsorbed as evidenced with the band of the $\mathrm{C}-\mathrm{S}-\mathrm{H}$ bending mode. The electrostatic driving force is thus not as effective in supporting high coverage. Assessment of the influence of the $\mathrm{pH}$-value on the adsorbate orientation and consequently on scattered intensity is presently too speculative. The CVs (Fig. 1-3) do not provide quantitative information about degree of coverage or number of adsorbed species, thus they are not in contradiction to this explanation.

\section{Acknowledgements}

Financial support from the Fonds der Chemischen Industrie and the Deutsche Forschungsgemeinschaft and help in acquiring some spectra and CVs from Monique Helmert and Hamidreza Sardary are gratefully acknowledged. 


\section{References}

1 V. M. Mirsky, TRAC, 2002, 21, 439-450.

2 A. L. Eckermann, D. J. Feld, J. A. Shaw and T. J. Meade, Coord. Chem. Rev., 2010, 254, 1769-1802.

3 J. Zhang, A. C. Welinder, Q. Chi and J. Ulstrup, Phys. Chem. Chem. Phys., 2011, 13, 5526-5545.

4 V. S. Dilimon, S. Rajalingam, J. Delhalle and Z. Mekhalif, Phys. Chem. Chem. Phys., 2013, 15, 16648-16656.

5 T. Baunach, V. Ivanova, D. A. Scherson and D. M. Kolb, Langmuir, 2004, 20, 2797-2802.

6 E. Blomgren, J. O'M Bockris and C. Jesch, J. Phys. Chem., 1961, 65, 2000-2010.

7 J. O'M Bockris and K. T. Jeng, J. Electroanal. Chem., 1992, 330, 541-581.

8 For an overview of methods and results see: R. Holze, in Landolt-Börnstein: Numerical Data and Functional Relationships in Science and Technology, New Series, Group IV: Physical Chemistry, Volume 9: Electrochemistry, Subvolume A: Electrochemical Thermodynamics and Kinetics, ed. W. Martienssen and M. D. Lechner, Springer-Verlag, Berlin, 2007.

9 A. Ulman, Chem. Rev., 1996, 96, 1533-1554.

10 C. A. Szafranski, W. Tanner, P. E. Laibinis and R. L. Garrell, Langmuir, 1998, 14, 3570-3579.

11 For a recent overview see: G. McNay, D. Eustace, W. E. Smith, K. Faulds and D. Graham, Appl. Spectrosc., 2011, 65, 825-837.

12 K. Carron and L. G. Hurley, J. Phys. Chem., 1991, 95, 9979-9984.

13 S. J. Li, D. Y. Wu, X. Y. Xu and R. N. Gu, J. Raman Spectrosc., 2007, 38, 1436-1443.

14 S. K. Saikin, Y. Z. Chu, D. Rappoport, K. B. Crozier and A. Aspuru-Guzik, J. Phys. Chem. Lett., 2010, 1, 2740-2746.

15 H.-L. Wu, H.-R. Tsai, Y.-T. Hung, K.-U. Lao, C.-W. Liao, P.-J. Chung, J.-S. Huang, I.-C. Chen and M. H. Huang, Inorg. Chem., 2011, 50, 8106-8111.

16 X.-Y. Xu, S.-J. Li, D.-Y. Wu and R.-A. Gu, Acta Chim. Sin., 2007, 65, 1095-1100.

17 J. Nara, S. Higai, Y. Morikawa and T. Ohno, J. Chem. Phys., 2004, 120, 6705-6711.

18 S. M. Ansar, X. Li, S. Zou and D. Zhang, J. Phys. Chem. Lett., 2012, 3, 560-565.

19 H. Yang, N. Gozubenli, Y. Fang and P. Jiang, Langmuir, 2013, 29, 7674-7681.

20 Y. Jiao, D. S. Koktysh, N. Phambu and S. M. Weiss, Appl. Phys. Lett., 2010, 97, 53125.

21 J. Fontana, J. Livenere, F. J. Bezares, J. D. Caldwell, R. Rendell and B. R. Ratna, Appl. Phys. Lett., 2013, 102, 201606.

22 T. T. Nhung, Y. Bu and S.-W. Lee, J. Cryst. Growth, 2013, 373, 132-137.

23 W. Hüttner, K. Christou, A. Göhmann, V. Beushausen and H. Wackerbarth, Microfluid. Nanofluid., 2012, 12, 521-527.

24 M. Moskovits, Phys. Chem. Chem. Phys., 2013, 15, 5301-5311.

25 J. R. Lombardi and R. L. Birke, J. Chem. Phys., 2012, 136, 144704.

26 J. R. Lombardi and R. L. Birke, J. Phys. Chem. C, 2008, 112, 5605-5617.

27 S. W. Joo, Chem. Lett., 2004, 33, 60-61.
28 H. Xu, C. H. Tseng, T. J. Vickers, C. K. Mann and J. B. Schlenoff, Surf. Sci., 1994, 311, L707-L711.

29 M. A. Mahmoud and M. A. El-Sayed, Nano Lett., 2009, 9, 3025-3031.

30 K. D. Alexander, M. J. Hampton, S. P. Zhang, A. Dhawan, H. X. Xu and R. Lopez, J. Raman Spectrosc., 2009, 40, 2171-2175.

31 C. E. Taylor, J. E. Pemberton, G. G. Goodman and M. H. Schoenfisch, Appl. Spectrosc., 1999, 53, 1212-1221.

32 R. Buividas, N. Fahim, J. Juodkazyte and S. Juodkazis, Appl. Phys. A: Mater. Sci. Process., 2014, 114, 169-175.

33 B. Ren, G. Picardi, B. Pettinger, R. Schuster and G. Ertl, Angew. Chem., Int. Ed., 2005, 44, 139-142.

34 J. M. Marr and Z. D. Schultz, J. Phys. Chem. Lett., 2013, 4, 3268-3272.

35 X. M. Fan, W. J. Zou, R. A. Gu and J. L. Yao, Chem. J. Chin. Univ., 2008, 29, 130-134.

36 M. Wang, J. L. Yao and R. A. Gu, Chem. J. Chin. Univ., 2006, 27, 1518-1521.

37 X. Li, M. Cao, H. Zhang, L. Zhou, S. Cheng, J.-L. Yao and L.-J. Fan, J. Colloid Interface Sci., 2012, 382, 28-35.

38 L. Ling, M. M. Xu, R. A. Gu and J. L. Yao, Acta Chim. Sin., 2007, 65, 779-784.

39 Y. Cui, B. Ren, J. L. Yao, R. A. Gu and Z. Q. Tian, J. Phys. Chem. B, 2006, 110, 4002-4006.

40 C. C. Chang, H. L. Wu, C. H. Kuo and M. H. Huang, Chem. Mater., 2008, 20, 7570-7574.

41 M. A. Mahmoud, Langmuir, 2013, 29, 6253-6261.

42 M. A. Mahmoud and M. A. El-Sayed, J. Phys. Chem. B, 2013, 117, 4468-4477.

43 T. Bhuvana, G. V. P. Kumar, G. U. Kulkarni and C. Narayana, J. Phys. Chem. C, 2007, 111, 6700-6705.

44 Y. N. Kim, S. H. Yoo and S. O. Cho, J. Phys. Chem. C, 2009, 113, 618-623.

45 S. J. Li and R. A. Gu, Acta Chim. Sin., 2004, 62, 2118-2122.

46 M. Ge, F. Bao, J. L. Yao, R. Sun and R. A. Gu, Acta Chim. Sin., 2009, 67, 2285-2289.

47 Y.-T. Tao, C.-C. Wu, J.-Y. Eu, W.-L. Lin, K.-C. Wu and C.-H. Chen, Langmuir, 1997, 13, 4018-4023.

48 H. Sellers, A. Ulman, Y. Shnidman and J. E. Eilers, J. Am. Chem. Soc., 1993, 115, 9389-9401.

49 M. Tachibana, K. Yoshizawa, A. Ogawa, H. Fujimoto and R. Hoffmann, J. Phys. Chem. B, 2002, 106, 12727-12736.

50 E. Sabatani, J. Cohen-Boulakia, M. Bruening and I. Rubinstein, Langmuir, 1993, 9, 2974-2981.

51 K. S. Shin, J. Raman Spectrosc., 2008, 39, 468-473.

52 M. Futamata, J. Phys. Chem., 1995, 99, 11901-11908.

53 H. M. Lee, M. S. Kim and K. Kim, Vib. Spectrosc., 1994, 6, 205-214.

54 C. J. Sandroff and D. R. Herschbach, J. Phys. Chem., 1982, 86, 3277-3279.

55 M. Takahashi, M. Fujita and M. Ito, Surf. Sci., 1985, 158, 307-313.

56 M. Takahashi and M. Ito, Chem. Phys. Lett., 1984, 103, 512-516. 57 M. Takahashi, M. Fujita and M. Ito, Chem. Phys. Lett., 1984, 109, 122-127. 
58 T. H. Joo, K. Kim and M. S. Kim, J. Raman Spectrosc., 1987, 18, 57-60.

59 F. G. Will and H. J. Hess, J. Electrochem. Soc., 1973, 120, 1-11. 60 F. G. Will, J. Electrochem. Soc., 1986, 133, 454-455.

61 R. Holze, Surf. Sci., 1988, 202, L612-L620.

62 T. Sueoka, J. Inukai and M. Ito, J. Electron Spectrosc. Relat. Phenom., 1993, 64-65, 363-370.

63 N. Hassan and R. Holze, Elektrokhimiya, 2012, 48, 442-453; N. Hassan and R. Holze, Russ. J. Electrochem., 2012, 48, 401-411.

64 M. Bron and R. Holze, 205 ${ }^{\text {th }}$ Electrochemical Society Meeting, San Antonio, TX, USA, 2004, abstract \# 867.

65 M. Bron and R. Holze, J. Solid State Electrochem., submitted. 66 R. Holze, J. Solid State Electrochem., 2013, 17, 1869-1879.

67 K. W. F. Kohlrausch, Ramanspektren, Akademische Verlagsgesellschaft Becker \& Erler Leipzig, 1943.

68 D. W. Scott, J. P. McCullough, W. N. Hubbard, J. F. Messerly, I. A. Hossenlopp, F. R. Frow and G. Waddington, J. Am. Chem. Soc., 1956, 78, 5463-5468.

69 G. Varsányi, Assignments for Vibrational Spectra of Seven Hundred Benzene Derivatives, Adam Hilger, London, 1974.

70 J. H. S. Green, Spectrochim. Acta, 1968, 24A, 1627-1637.

71 A. Wokaun, J. P. Gordon and P. F. Liao, Phys. Rev. Lett., 1982, 48, 957-960.
72 F. R. Dollish, W. G. Fateley and F. F. Bentley, Characteristic Raman Frequencies of Organic Compounds, Wiley, New York, 1974.

73 R. Holze, Surface and Interface Analysis: An Electrochemists Toolbox, Springer-Verlag, Heidelberg, 2009.

74 S. W. Joo, S. W. Han and K. Kim, J. Phys. Chem. B, 2000, 104, 6218-6224.

75 S. W. Joo, S. W. Han and K. Kim, Appl. Spectrosc., 2000, 54, 378-383.

76 H. Kang, J. Noh, E. O. Ganbold, D. Uuriintuya, M. S. Gong, J. J. Oh and S. W. Joo, J. Colloid Interface Sci., 2009, 336, 648-653.

77 R. G. Greenler, J. Chem. Phys., 1966, 44, 310-315.

78 M. Moskovits, D. P. DiLella and K. J. Maynard, Langmuir, 1988, 4, 67-76.

79 M. Moskovits, J. Chem. Phys., 1982, 77, 4408-4416.

80 J. S. Suh and M. Moskovits, J. Am. Chem. Soc., 1986, 108, 4711-4718.

81 M. Moskovits and J. S. Suh, J. Phys. Chem., 1984, 88, 5526-5530.

82 R. A. Wolkow and M. Moskovits, J. Chem. Phys., 1992, 96, 3966-3980.

83 J. E. Pemberton, M. A. Bryant, R. L. Sobocinski and S. L. Joa, The 1991 Pittsburgh Conference, Chicago, Ill, USA, 1991, abstr. 748.

84 R. Holze, Bull. Electrochem., 1994, 10, 45-55. 